\title{
ALGUNAS CONSIDERACIONES \\ EN TORNO AL CONTRATO \\ DE TRANSPORTE MARÍTIMO BAJO \\ RÉGIMEN DE CONOCIMIENTO \\ DE EMBARQUE CHILENO \\ DESDE LA PERSPECTIVA DEL NUEVO \\ DERECHO DE LA CONTRATACIÓN
}

\section{SOME CONSIDERATIONS RELATED}

TO THE CHILEAN MARITIME

TRANSPORTATION CONTRACT UNDER

THE BILL OF LADING REGIME FROM

THE PERSPECTIVE OF THE NEW

CONTRACT LAW

\author{
Mario Opazo González*
}

RESUMEN

El denominado nuevo derecho de la contratación, surgido principalmente a partir de laCISG, ha significado un cambio en la forma de concebir al contrato, al incumplimiento y a la forma de estructurar los remedios contractuales por incumplimiento. En este sentido, la doctrina contemporánea ha hecho esfuerzos por demostrar que las reglas del nuevo derecho de los contratos son aplicables en Chile y, por tanto, también los remedios en caso de inejecución. En este contexto, el presente trabajo pretende analizar la figura del contrato de transporte marítimo bajo régimen de conocimiento de embarque chileno desde la perspectiva del nuevo derecho de la contratación y examinar de qué manera esta nueva concepción influye en la noción de incumplimiento y en los remedios en caso de inejecución, con especial énfasis en la indemnización de perjuicios.

* Correo postal: Uno Norte 3041, Viña del Mar. Escuela de Derecho, Facultad de Derecho, Universidad Santo Tomás, Chile y universidades de Valparaíso y de Viña del Mar. Correo electrónico: marioopazo@santotomas.cl. Artículo recibido el 8 de octubre de 2018 y aceptado para su publicación el 10 de mayo de 2019. 
Palabras Claves: Contrato de transporte marítimo bajo régimen de conocimiento de embarque, nuevo derecho de la contratación, derecho chileno.

\section{AbStract}

The new Contract Law that has emerged from the CISG has meant a change in the way of conceiving the contract, the breach and the way of structuring the contract remedies in case of breach. In this way, the modern doctrine has made its efforts to prove that the rules of the new Contract Law can be applied in Chile and, therefore, the remedies in case of contract breach are also applicable. In this context, the present work aims to analyze the Chilean maritime transportation contract under the Bill of Lading regime from the perspective of the new Contract Law and to examine how this new conception influences the notion of breach and the remedies in case of contract breach, emphasizing the compensation remedy.

Key words: Maritime Transportation Contract Under Bill Of Lading Regime, new Contract Law, Chilean Law.

\section{INTRODUCCIÓN}

Como es sabido, en los últimos años ha comenzado a tomar fuerza una corriente renovadora en materia de obligaciones y contratos, denominada nuevo derecho de la contratación o nuevo derecho de los contratos; de esta manera, doctrinariamente se ha formulado una distinción entre la denominada doctrina clásica, sustentada durante el siglo pasado, y la doctrina contemporánea, constituida por el nuevo derecho de la contratación ${ }^{1}$.

La doctrina clásica constituyó la manera predominante de comprender el fenómeno contractual durante el siglo xx, aplicando sus postulados no solo a los contratos civiles, sino, también, a los que escapan a la regla-

${ }^{1}$ Como explica Álvaro Vidal, esta tendencia renovadora de la doctrina nacional ha buscado reinterpretar las disposiciones del Código Civil chileno sobre el incumplimiento y sus efectos, siguiendo la disciplina y los principios del denominado Soft Law, recogido de manera fundamental en la CISG, los Principios de UNIDROIT y los PECL. VIDAL (2011), p. 245. Reitera esta idea al sostener: "en el caso chileno, con un esfuerzo dogmático importante, siguiendo el modelo de la CISG y la doctrina de derecho de contratos comparado más autorizada, se ha avanzado en desplazar la diversidad de regímenes especiales según la concreción del incumplimiento del vendedor por un régimen único, el general al incumplimiento contractual sometido al tipo de la compraventa y a las reglas de los efectos de las obligaciones". VIDAL (2017), pp. 234-235. 
mentación del Código Civil, como es el caso del contrato de transporte marítimo bajo régimen de conocimiento de embarque.

Como se adelantó, el cambio de siglo ha implicado el impulso de esta nueva forma de entender el fenómeno contractual; de esta manera, se ha propuesto una modificación en la forma de entender la noción de contrato, la formación del mismo, la noción de incumplimiento contractual y los remedios de que dispone el acreedor frente a la inejecución del deudor. Del mismo modo, ha comenzado a realizarse el análisis de ciertos tipos contractuales, como la compraventa y el contrato de servicios, desde la perspectiva del nuevo derecho de la contratación.

En este contexto, el propósito del presente trabajo consiste en determinar de qué manera cambia nuestra forma de entender el contrato de transporte marítimo bajo régimen de conocimiento de embarque chileno, si se examina a partir de los postulados del nuevo derecho de la contratación, en particular, en lo que se refiere al inejecución de los distintos actores que intervienen en la operación de transporte marítimo y en los remedios contractuales que los mismos pueden emplear en caso de incumplimiento.

Para estos efectos, se considerará la modificación en cuanto a la noción de incumplimiento en el contrato de transporte marítimo bajo régimen de conocimiento de embarque y la incidencia de los remedios contractuales frente a la inejecución de los distintos agentes involucrados en la empresa de transporte marítimo, haciendo el correspondiente contraste entre el análisis formulado por la doctrina tradicional y la forma de entender los aspectos señalados del contrato de transporte marítimo bajo régimen de conocimiento de embarque desde la perspectiva del nuevo derecho de la contratación, con especial énfasis en la indemnización de perjuicios.

$\mathrm{El}$ análisis que se propone se basará fundamentalmente en el derecho nacional que, como es sabido, se encuentra regulado en el libro III del Código de Comercio, el cual, a su turno, encuentra su base en las denominadas Reglas de Hamburgo, sin perjuicio de las necesarias referencias a la doctrina y jurisprudencia nacionales. En consecuencia, no se abordará el análisis comparado de ordenamientos que han adoptado sistemas diferentes a los nuestros, como ocurre con aquellos que han seguido las Reglas de La Haya-Visby, lo que incluye a los países del sistema anglosajón.

\section{Cuestión previa:}

LA COMPATIBILIDAD ENTRE EL ORDENAMIENTO JURÍDICO CHILENO Y EL NUEVO DERECHO DE LA CONTRATACIÓN

Sabido es que la doctrina nacional de manera tradicional ha entendido que el contrato es una convención generadora de derechos personales y 
obligaciones ${ }^{2}$. Esta forma de entender, de carácter dogmático y abstracto, ha encontrado su fundamento en el principio de la autonomía privada ${ }^{3}$.

De la misma manera, se ha estudiado la relación obligatoria contractual dentro del ámbito más amplio correspondiente a la relación obligatoria en general, es decir, se ha estudiado dicha relación, cualquiera que sea su fuente, sin hacer referencia a las particularidades del vínculo obligacional que nace del contrato ${ }^{4}$. En este sentido, como plantea la profesora Claudia Mejías, el modelo de obligación que se ha empleado para hacer el análisis de la relación obligatoria ha sido la obligación unilateral de dar una especie o cuerpo cierto ${ }^{5}$.

Como consecuencia de lo anterior, el vínculo obligacional contractual se ha entendido como una noción abstracta, en la que es posible encontrar dos sujetos: acreedor y deudor, en virtud de la cual el segundo debe ejecutar una determinada prestación a favor del primero, el cual está facultado para exigir el cumplimiento de dicha prestación ${ }^{6}$.

En este contexto, el contrato se examina como una de las fuentes de las obligaciones y, como se adelantó, se funda en el dogma de la autonomía privada$^{7}$. De esta manera, el contenido contractual se analiza a partir de

${ }^{2}$ López y Elorriaga (2017), p. 3. En el mismo sentido, para Arturo Alessandri y Manuel Somarriva es "el acuerdo de voluntades de dos o más personas destinado a crear obligaciones”. Alessandri, Somarriva y Vodanovic (1942), p. 16.

${ }^{3}$ LÓPez y Elorriaga (2017), pp. 3-4.

${ }^{4}$ Alessandri et al. (2016), pp. 13-14.

${ }^{5}$ Mejías (2011), p. 83.

${ }^{6}$ Meza (2007), pp. 9-10. Este fenómeno no es exclusivo de nuestro país, sino que es posible advertir que el mismo se ha producido en otros ordenamientos, por ejemplo, en Argentina, Jorge Llambías, Patricio Raffo y Rafael Sassot también definen la obligación como "la relación jurídica en virtud de la cual alguien denominado deudor debe satisfacer una prestación a favor de otro llamado acreedor”. Llambías et al. (2005), p. 11. En España, Esther Monterroso la define como "aquella relación jurídica constituida con base en unos hechos, por la que una persona, llamada acreedor, tiene el derecho a exigir de otra, llamada deudor, el cumplimiento de una determinada prestación, teniendo esta última el deber jurídico de cumplirla”. Monterroso (2014), p. 18; en el mismo sentido De Pablo et al. (2014), p. 47. Una situación similar se ha presentado en Francia; así, Joseph Pothier señala que es "un lazo de derecho, que nos restringe a dar a otro alguna cosa, o bien, a hacer o no hacer tal o cual cosa". Pothier (1993), p. 7; Louis Josserand entiende que "es una relación jurídica que asigna, a una o a varias personas, la posición de deudores frente a otra u otras, que desempeñan el papel de acreedores y respecto de las cuales están obligadas a una prestación, ya positiva (obligación de dar o de hacer), ya negativa (obligación de no hacer)". Josserand (2008), p. 7; en el mismo sentido, para Yvaine Buffelan-Lanore y Virginie Larribau-Terneyre, es "un vínculo de derecho por el cual una persona está compelida hacia otra a una prestación o a una abstención”. BUFFELAN-LANORE y Larribau-Terneyre (2014), p. 5 (traducción libre).

${ }^{7}$ Prado (2015a), p. 10. Pamela Prado agrega que este principio sirve de fundamento a los demás principios de la contratación e inspira el sistema subjetivo de interpretación contractual. 
las obligaciones que engendra: si es unilateral, se observa la obligación contraída por la parte que resulta obligada y, si es bilateral, se observan las obligaciones recíprocas asumidas por las partes.

Esta forma tradicional de concebir la obligación ha resultado ser insuficiente. Por una parte, como señala Pamela Prado, no es efectivo que solo exista una obligación para cada parte, sino que, dentro de los efectos que produce el contrato, es posible identificar obligaciones primordiales distinguiéndolas de las obligaciones funcionales. Las primeras son las que efectivamente permiten la satisfacción de los intereses de las partes, mientras que las segundas son las que posibilitan el cumplimiento de las primeras ${ }^{8}$.

Desde otra perspectiva, como lo ha señalado la doctrina contemporánea, el modelo se construye a partir de la obligación de objeto fungible ${ }^{9}$, sea que se trate de dar o de hacer ${ }^{10}$.

Por otra parte, el denominado nuevo derecho de la contratación ${ }^{11}$ ha significado un cambio importante en la forma de entender al contrato. En efecto, se ha sostenido que se concibe, en primer lugar,

"como un instrumento a través del cual los sujetos regulan sus relaciones jurídico-económicas, con la finalidad de conseguir sus particulares propósitos" ${ }^{\prime 2}$;

como consecuencia de lo anterior, cuando una persona celebra un contrato, lo que busca es satisfacer determinados intereses, por lo que el ordenamiento debería privilegiar dichos intereses y su plena satisfacción ${ }^{13}$. De esta manera, se abandona su concepción dogmática y se asume una concepción práctica o pragmática del mismo ${ }^{14}$.

Junto con lo anterior, debe tenerse presente que la doctrina nacional ha sostenido que la concepción del nuevo derecho de la contratación es

${ }^{8}$ Prado (2015a), p. 21.

${ }^{9}$ Vidal (2009a), p. 508. Agrega que una obligación es fungible cuando su objeto sea recíprocamente sustituible o intercambiable por otro, sin lesionar la efectiva satisfacción del interés del acreedor. VIDAL (2009a), p. 509.

${ }^{10}$ Carlos Pizarro se refiere a las obligaciones genéricas y, en gran medida, los contratos de prestación de servicios que generan obligaciones de hacer. PiZARro (2008a) p. 398.

${ }^{11}$ Antonio Morales Moreno lo entiende como "una nueva construcción del derecho contractual, surgida en el derecho uniforme, por necesidades del comercio internacional, que ha ejercido y continúa ejerciendo influencia en la modernización del derecho de obligaciones continental”. Morales (2006), p. 25.

${ }^{12}$ Prado (2015a), p. 21.

${ }^{13}$ Ibid.

${ }^{14}$ Ibid. En el mismo sentido, Álvaro Vidal habla de una noción realista del contrato. VIDAL (2009b), p. 226. 
perfectamente compatible con el ordenamiento jurídico chileno ${ }^{15}$. Como consecuencia de lo señalado, la forma de concebir el contrato del nuevo derecho de la contratación no solo resulta por completo aplicable al contrato de transporte marítimo bajo régimen de conocimiento de embarque, sino que, además, se adecua mejor a las particularidades del mismo.

En efecto, la concepción de obligación ha dejado de ser una figura abstracta para centrarse en la relación contractual. Desde esta perspectiva, como se señaló, dentro del contrato es dable identificar obligaciones primordiales y deberes secundarios de conducta. Como es posible identificar obligaciones de una y otra naturaleza para cada parte, la calificación de acreedor, deudor contractual o ambas se torna, en numerosas ocasiones, muy dificultosa, puesto que, durante la vigencia de la relación contractual, este se muestra como un proceso en que las calidades de deudor, acreedor o ambas se van adquiriendo dependiendo de la obligación de que se trate, en una suerte de espiral de intercambio continuo de papeles, razón por la cual es más adecuado hablar de contratantes o de partes, que de deudor, acreedor o ambos ${ }^{16}$. Esta concepción es perfectamente compatible con el contrato de transporte marítimo bajo régimen de conocimiento de embarque, ya que es posible identificar obligaciones principales (conducir las mercancías para el transportista y pagar el flete para el cargador) y obligaciones secundarias (como recibir y cuidar de las mercancías ${ }^{17}$, avisar su llegada y entregarlas al consignatario para el transportista, y entregar las mercancías, suministrar todos los antecedentes y documentos necesarios, describir fidedignamente la mercancía e indicar si la mercancía es peligrosa, para el cargador). Sin perjuicio de lo anterior, también es posible que el consignatario -tercero extraño al contrato de transporte marítimo bajo régimen de conocimiento de embarque- adquiera obligaciones principales y secundarias.

\section{LA NOCIÓN DE INCUMPLIMIENTO EN EL CONTRATO DE TRANSPORTE MARÍTIMO BAJO RÉGIMEN DE CONOCIMIENTO DE EMBARQUE}

El tema del incumplimiento y de los remedios contractuales se ha estructurado de una manera inorgánica en el Código Civil, configurándose a partir de la inejecución de la obligación en general. En este sentido, el tema de la responsabilidad civil se ha entendido como sinónimo de indemniza-

${ }^{15}$ Prado (2012), pp. 307-323.

${ }^{16}$ Prado (2015a), pp. 21-22.

${ }^{17}$ Como explica Pamela Prado, el deber de conservación es un ejemplo típico de deber secundario de conducta. Prado (2015a), p. 43. 
ción de perjuicios, prescindiendo de los demás remedios contractuales ${ }^{18}$, y se ha estructurado tomando como paradigma la obligación de dar una especie o cuerpo cierto.

Esta forma clásica de entender el contrato y los efectos de su inejecución, se ha traducido en estudiar el incumplimiento resolutorio (llamado "condición resolutoria tácita") a propósito de las condiciones ${ }^{19}$; extender la imputabilidad como requisito a todos los remedios contractuales ${ }^{20}$; estudiar la pérdida de la cosa que se debe como un modo de extinguir las obligaciones ${ }^{21}$; entender que el efecto del caso fortuito o fuerza mayor es excluir la culpabilidad ${ }^{22}$, etcétera.

Por su parte, en el nuevo derecho de la contratación, esta nueva forma de concebir al contrato implica, al mismo tiempo, establecer transformaciones importantes en la forma de entender el incumplimiento y los remedios en caso de inejecución. En efecto, como señala Pamela Prado, la perspectiva práctica del contrato se traduce en concebir una noción amplia, abstracta y objetiva del incumplimiento, que sirve de fundamento de todos los remedios contractuales de que dispone el acreedor para obtener la satisfacción de su interés; de esta manera, se separa lo que es el incumplimiento de lo que es la imputabilidad, exigiéndose esta última solo para la indemnización de perjuicios ${ }^{23}$. En el mismo sentido, Claudia Mejías entiende que el incumplimiento es cualquiera desviación del programa contractual idealmente convenido, es decir, se trata de una noción amplia y objetiva que se centra en la satisfacción del interés del acreedor ${ }^{24}$.

${ }^{18}$ Morales (2006), p. 21.

${ }^{19}$ Entre varios: Abeliuk (2014), pp. 643-660; Alessandri et al. (2016), pp. 244-251; Alessandri (1998), pp. 195-201; Ramos (2008), pp. 159-179; Meza (2007), pp. 41-44; Troncoso (2011), pp. 34-45; Ruz (2011), pp. 195-206.

${ }^{20}$ Así, por ejemplo, René Abeliuk, al referirse a la denominada "condición resolutoria tácita" del artículo 1489 del $C C$, exige, como requisito para su procedencia, que se trate de un incumplimiento imputable. ABELIUK (2014), pp. 647 y 655. En el mismo sentido, Ramos (2008), p. 166; Meza (2007), pp. 42-43; Court y Wegner (2013), p. 173; Troncoso (2011), p. 139.

${ }^{21}$ Entre otros: Alessandri (1998), pp. 467-472; RAmos (2008), p. 438; RuZ (2011), p. 477; Troncoso (2011), p. 235; Meza (2007), pp. 225-229.

22 Alessandri (1998), p. 82.

${ }^{23}$ Prado (2015a), pp. 29-30.

${ }^{24}$ Mejías (2011), p. 89. Ya Antonio Morales planteaba que el incumplimiento es cualquiera desviación de las exigencias del contrato en el desenvolvimiento o en la ejecución del mismo. Morales (2006), p. 29. En el mismo sentido, Carlos Pizarro también sostiene que debe adoptarse una noción objetiva de incumplimiento, entendido como la incorrecta prestación de lo pactado. PizArRo (2008a), p. 399. Apunta en la misma dirección Hernán Corral, para quien esta noción objetiva consiste en toda conducta, activa u omisiva, realizada por el deudor o sus auxiliares, que contravienen lo prometido en el contrato, frustrando de esta manera el interés del acreedor, agregando que se trataría de una noción 
Por otro lado, como ya se señaló, el paradigma de obligación ha dejado de ser la de dar una especie o cuerpo cierto, pasando a ser la de objeto fungible (dar una cosa genérica o la de hacer, por regla general ${ }^{25}$; como consecuencia de ello, la pérdida de la cosa que se debe solo de manera excepcional puede operar como modo de extinguir, ya que solo tiene aplicación en las obligaciones de dar una especie o cuerpo cierto, y se concibe, más bien, a la imposibilidad de cumplimiento, pero como causal de exoneración de responsabilidad ${ }^{26}$. De la misma manera, se ha entendido que el efecto del caso fortuito o fuerza mayor es excluir la relación de causalidad ${ }^{27}$, pues formaría parte de lo que un sector de la doctrina ha denominado "causa extraña"

Teniendo presente estos cambios en la forma de entender el incumplimiento contractual, se examinará cómo se produce la inejecución de las distintas obligaciones que surgen del contrato de transporte marítimo bajo régimen de conocimiento de embarque, tanto desde la perspectiva clásica como desde el nuevo derecho de la contratación.

A partir del art. 974 del C. de C. se desprende que el contrato de transporte marítimo bajo régimen de conocimiento de embarque es bilateral, ya que surgen obligaciones recíprocas para ambas partes. Así, el porteador se obliga al traslado de la mercancía ${ }^{29}$ de un puerto a otro; mientras que el cargador se obliga a pagar un flete ${ }^{30}$.

Además, la ley reconoce otras obligaciones que surgen para los intervinientes de la operación de transporte ${ }^{31}$, de manera que es distinguir:

objetiva, pues consiste en comparar la conducta esperable según el contrato y aquella que efectivamente se produjo en la realidad. Corral (2010), pp. 153-154.

${ }^{25}$ VIDAL (2009a), pp. 499 y 508.

${ }^{26}$ Como explica María Graciela Brantt, en el nuevo derecho de la contratación se considera la imposibilidad de cumplimiento como causa de exoneración que no necesariamente coincide con la extinción de la relación obligatoria. Ello es consecuencia del modelo adoptado por el nuevo derecho de la contratación, obligación de contenido fungible, por lo que una vez superada la imposibilidad de cumplimiento, el deudor debe cumplir, ya que no se ha extinguido el vínculo obligacional. BrantT (2010), pp. 188-190.

${ }^{27}$ Corral (2013), p. 193; Tamayo (2007), tomo il, p. 10; Salinas (2011), p. 492.

${ }^{28}$ TAMAYo (2007), tomo II, p. 16.

${ }^{29} \mathrm{El}$ art. 975 del C. de C. define mercancía como "toda clase de bienes muebles, comprendiendo también los animales vivos".

${ }^{30}$ Cabe tener presente que Claudio Barroilhet explica que esta es una regla general, pero que nada impide que pueda estipularse que el flete será pagado por el consignatario. BARRoilhet (2014), p. 466.

${ }^{31}$ Es preferible hablar de intervinientes y no de contratantes, toda vez que -de conformidad con el C. de C.- también surgen derechos y obligaciones para el consignatario, no obstante que este no es parte del contrato de transporte marítimo. 


\section{a) Obligaciones del cargador}

\section{a.1 Pagar un flete ${ }^{32}$}

El Código de Comercio no establece reglas especiales en relación con el incumplimiento de esta obligación, de manera que, aplicando las reglas generales contenidas en el art. 1556 del $C C$, el cargador incumplirá cuando no pague el flete y el pago no sea de cargo del consignatario, o cuando lo pague parcial o tardíamente.

a.2 Entregar, al transportista o sus agentes, las mercancías o efectos objeto del transporte, en el lugar, tiempo y forma convenidos ${ }^{33}$

Claudio Barroilhet agrega que esta obligación no se encuentra explícita en la ley, pero resulta evidente que está implícita en el contrato de transporte marítimo, aplicando la buena fe integradora ${ }^{34}$.

El Código de Comercio no establece reglas especiales en relación con su incumplimiento, de manera que, aplicando las reglas generales contenidas en el art. 1556 del $C C$, el cargador la incumplirá cuando no entregue las mercancías o si, entregándolas al transportista, lo haga de manera parcial o tardía.

a.3 Suministrar al transportista todos los antecedentes

y documentos que sean necesarios para el correcto y buen

éxito del contrato, por ejemplo, documentos de exportación, certificados sanitarios u otros que requiera la autoridad ${ }^{35}$.

Dado que el Código de Comercio no establece reglas especiales respecto del incumplimiento, aplicando las reglas generales contenidas en el art. 1556 del $C C$, debe entenderse que lo hay cuando no se proporciona ningún antecedente ni documento o, bien, cuando se proporcionan solo algunos, se proporcionan de manera tardía o los que se han proporcionado no son fidedignos o completos.

\section{a.4 Describir fidedignamente la mercancía} que embarca

Esta obligación se desprende del art. 1022 del C. de C., pues esta disposición establece la garantía del cargador respecto de la exactitud de los datos re-

${ }^{32}$ Ha de advertirse que Claudio Barroilhet explica que esta es una regla general, pero que nada impide que pueda estipularse que el flete será pagado por el consignatario. BARRoILHET (2014), p. 466.

${ }^{33}$ Contreras (2000), p. 219.

${ }^{34}$ Barroilhet (2014), p. 465.

${ }^{35}$ Contreras (2000), pp. 219-220. 
lativos a la naturaleza general de las mercancías, sus marcas, número, peso y cantidad que haya proporcionado para su inclusión en el conocimiento de embarque. Agrega que el cargador indemnizará al transportista de los perjuicios resultantes de la inexactitud de esos datos. En consecuencia, se entiende que se trata de una obligación implícita al suministro de datos acerca de la mercancía que el cargador embarca, es decir, la ley entiende que la información que suministra el cargador es íntegra y verídica, de ahí que se hace responsable de su integridad y fidelidad ${ }^{36}$.

Según el art. 1022 del C. de C. no hay cumplimiento cuando los datos proporcionados por el cargador al transportista son inexactos, esto es, cuando la descripción hecha por el cargador no coincide con la realidad de la naturaleza, marcas, número, peso y cantidad de las mercancías entregadas al transportista.

a.5 Indicar la peligrosidad de las mercancías que embarca ${ }^{37}$

A partir del art. 1013 del C. de C., se desprende que esta obligación comprende $^{38}$ :

i) Informar el carácter peligroso de las mercancías al transportista.

ii) Identificar adecuadamente, mediante marcas o etiquetas, las mercancías peligrosas.

iii) Informar al transportista de las precauciones que deban adoptarse para su manipulación.

A partir de lo dispuesto en el art. 1013 del C. de C., se entiende que el cargador no cumple cuando no informa el carácter peligroso de la mercancía; no identifica de manera adecuada las mercancías peligrosas, o no informa de las precauciones que deban adoptarse para su manipulación. Ha de entenderse que, además, no cumplirá si la información a que se refiere la disposición y que debe proporcionar no es completa o fidedigna.

\section{b) Obligaciones del transportista}

b.1 Trasladar la mercancía ${ }^{39}$ de un puerto a otro

b.2 Recibir la carga en la forma, lugar y oportunidad convenidos con el cargador $^{40}$

${ }^{36}$ Barroilhet (2014), p. 461.

${ }^{37}$ Op. cit., p. 464.

${ }^{38}$ Ibid.

${ }^{39} \mathrm{El}$ art. 975 del C. de C. define mercancía como "toda clase de bienes muebles, comprendiendo también los animales vivos".

${ }^{40}$ Contreras (2000), p. 220. 


\section{b.3 Cuidar la carga ${ }^{41}$}

Consiste en que el transportista debe entregarla en destino en las mismas condiciones que la recibió en origen; por esta razón es importante la presunción de veracidad del conocimiento de embarque, en cuanto recibo de la mercancía. Se trata, por tanto, de una obligación de resultado ${ }^{42}$. Se agrega que el transportista debe emplear una diligencia o cuidado medio ${ }^{43,44}$.

\section{b.4 Suministrar ventilación y temperatura al contenedor que contiene productos congelados o refrigerados ${ }^{45}$}

Claudio Barroilhet agrega que se ha discutido si es una obligación de medios, que se limita a programar los sistemas de ventilación y generadores de temperatura de la unidad de transporte en ciertos grados y frecuencias que permitan mantener la temperatura en los niveles acordados, pero sin que esto implique un resultado, consistente en que las mercancías que están dentro de dicha unidad se mantengan de manera efectiva en la temperatura programada; mientras que otros entienden que se trata de una obligación de resultado consistente en mantener cierta temperatura y ventilación ${ }^{46,47}$.

b.5 Avisar a una persona determinada, llamada notify party (parte notificada), la llegada de la mercancía en destino, aunque se ha discutido por algunos su naturaleza de obligación legal, señalándose que, en rigor, se trata de un simple aviso de cortesía ${ }^{48}$

${ }^{41}$ Contreras (2000), p. 220.

${ }^{42}$ Barroilhet (2014) p. 468.

${ }^{43}$ Op. cit., p. 469.

${ }^{44}$ Se entiende que esta diligencia o cuidado a que alude Claudio Barroilhet corresponde a la diligencia promotora. VIDAL (2007b), p. 46.

${ }^{45}$ Barroilhet (2014), p. 469.

${ }^{46} \mathrm{Ibid}$.

${ }^{47}$ En este punto, Claudio Barroilhet incurre en un error: en ambos casos se trata de una obligación de resultado (suministrar una temperatura o mantener una temperatura), pues en ambos casos la prestación consiste en la obtención de un resultado y no en un actuar diligente. Lo que, en realidad, ocurre es que se discute el contenido de la obligación: suministrar una temperatura determinada o mantener una temperatura determinada en el interior del contenedor, pero no puede sostenerse que sea una obligación de medios, pues ello implicaría sostener que se trata de una obligación de mera actividad, lo que no es correcto.

${ }^{48}$ Barroilhet (2014), p. 469. 
b.6 Entregar la carga al consignatario

o a su orden ${ }^{49}$

Claudio Barroilhet agrega que, fuera de las obligaciones reguladas de manera imperativa por la ley, las partes son libres para incorporar otras obligaciones, que construirían elementos accidentales del contrato ${ }^{50}$.

A partir de estas seis obligaciones que surgen para el transportista marítimo, la doctrina tradicional ha señalado que el transportista marítimo es responsable por la pérdida o daño de la mercancía, así como del retraso en su entrega, que ocurran mientras la mercancía está bajo su custodia ${ }^{51}$. De ahí que Jaime Carvallo sostenga que el transportista responde en cuatro $\operatorname{casos}^{52}$ :

b.1 Pérdida de la mercancía, lo que significa

Que la cosa embarcada no llegó a destino

Claudio Barroilhet sostiene que la pérdida se produce cuando la mercancía se destruye, aniquila, inutiliza, desaparece o hay privación de su tenencia, por ejemplo, cuando se incendia, arroja al mar, se la roban o cae en decomiso, etcétera ${ }^{53}$.

Para Leslie Tomasello, la pérdida es la destrucción total de la mercancía ${ }^{54}$.

Claudio Barroilhet y Alejandro Díaz agregan que la pérdida está regulada en el art. 986 del $C$. de $C$., conforme al cual habrá pérdida si, dentro de los sesenta días siguientes a la expiración del plazo de entrega acordado de forma expresa o el razonablemente exigible de un transportador diligente, la mercancía no fue entregada. Por lo tanto, la pérdida es el retraso más sesenta días ${ }^{55}$.

Según Claudio Barroilhet, la pérdida parcial afecta a parte de la mercancía, cuando se trata de una mercancía fraccionable ${ }^{56}$.

Cabe tener presente que, para determinar cuando ha habido cumplimiento o incumplimiento de esta obligación, hay que comparar la carga efectivamente entregada al transportista con la carga que entrega al consignatario. Este ha sido el criterio de nuestra jurisprudencia; en un fallo de la Corte Suprema de 30 de mayo de $2002^{57}$, el máximo tribunal, acogiendo

${ }^{49}$ Contreras (2000), p. 220.

${ }^{50}$ Barroilhet (2014), p. 469.

${ }^{51}$ Ibid.

${ }^{52}$ Carvallo (1994), pp. 78-79.

${ }^{53}$ Barrollhet (2014), p. 475.

${ }^{54}$ Tomasello (2014), p. 472.

${ }^{55}$ Barroilhet y Díaz (2002), p. 246.

${ }^{56}$ Barrollhet (2014), p. 475.

${ }^{57}$ Rol n. ' 2107-2001, caratulados "Import Export Stop Ltda. c/ CSAV". 
un recurso de casación en el fondo, procedió a invalidar la sentencia de segunda instancia dictada por la Corte de Apelaciones de Iquique, que había dado lugar a la acción indemnizatoria por responsabilidad contractual del transportista marítimo y a dictar la correspondiente sentencia de reemplazo, rechazando la pretensión indemnizatoria del actor. Los tribunales de la instancia habían entendido que se habían embarcado seis vehículos, pero que solo habían llegado cuatro al puerto de destino. En cambio, el tribunal de casación entendió que -si bien en un comienzo se había reservado espacio para el envío de seis vehículos- las correcciones hechas al conocimiento de embarque daban cuenta de que el cargador había retirado dos de ellos, los cuales, por tanto, no fueron embarcados. Siendo esto así, en rigor no hubo pérdida parcial de la mercancía, sino que llegó la mercancía efectivamente embarcada.

\section{b.2 Merma, es decir, que la cosa ha disminuido ${ }^{58}$}

b.3 Daño, que significa cualquier disminución

de valor que tenga la mercancía

Para Leslie Tomasello, es su destrucción parcial ${ }^{59}$, mientras que para Osvaldo Contreras, hablar de daño es lo mismo que hablar de avería simple, la cual puede ser total o parcial ${ }^{60}$.

Claudio Barroilhet y Alejandro Díaz plantean que, en esta materia, cobran importancia las presunciones de veracidad y de buena entrega; la primera, al inicio del viaje; la segunda, a su término. De esta manera, se presume que el transportista recibió las mercancías en el estado señalado en el conocimiento de embarque y, si este nada dice, se presume que fueron recibidas en buen estado. Luego, al término del transporte, por el hecho de poner las mercancías en poder del consignatario, se presume, salvo prueba en contrario, que el transportista las ha entregado tal como aparece en el documento de transporte y si este no se ha emitido, en buen estado; esta presunción no opera si el consignatario ha dado al transportista aviso escrito de la pérdida o daño o si ellos se han comprobado en un examen o inspección conjunta de las partes, efectuada al momento en que el consignatario recibe las mercancías ${ }^{61}$.

En estos tres casos (pérdida, merma o daño), interesa saber qué ocurre si tales pérdidas, mermas o daños se han producido como consecuencia

\footnotetext{
${ }^{58}$ Según Claudio Barroilhet, la merma es la pérdida parcial que afecta a los graneles. BARROILHET (2014), p. 475.

${ }^{59}$ Tomasello (2014), p. 472.

${ }^{60}$ Contreras (2000), p. 262.

${ }^{61}$ Barroilhet y Díaz (2002), pp. 246-247.
} 
de un caso fortuito ${ }^{62}$. Como ha señalado la doctrina contemporánea, el efecto del caso fortuito es diferente, dependiendo de si se está frente a una obligación genérica o específica ${ }^{63}$.

Para abordar de manera adecuada este tema, es necesario plantearse uno previo: si la obligación del transportista marítimo de entregar la carga al consignatario o a su representante es de dar o de hacer ${ }^{64}$. No es del caso entrar en detalle en esta discusión, pues excede el propósito de este trabajo y solo reviste interés para esta investigación, en cuanto permite determinar los efectos del caso fortuito cuando la mercancía experimente mermas, pérdidas o daños mientras se encuentra bajo la custodia del transportista marítimo. La determinación del carácter de la obligación de entregar interesa para precisar si puede ser calificada o no de genérica o específica, pues, si bien hay autores que han sostenido que la clasificación entre obligaciones de género y de especie o cuerpo cierto es exclusiva de las obligaciones de dar ${ }^{65}$, ha de estimarse que las obligaciones de hacer también pueden ser genéricas o específicas ${ }^{66}$ o, como plantea Álvaro Vidal, pueden ser fungibles o no fungibles ${ }^{67}$.

Dado que se considera que tanto las obligaciones de dar como las de hacer pueden ser genéricas o específicas, la obligación de entregar que recae sobre el transportista marítimo también puede ser clasificada de

${ }^{62}$ Se entiende que el caso fortuito operará como causal de exoneración de responsabilidad en la medida en que se dé cumplimiento a lo dispuesto en el art. 984 del Código de Comercio, esto es, en la medida que el transportista, sus agentes o dependientes hayan tomado todas las medidas que razonablemente podían exigirse para evitar el hecho y sus consecuencias.

${ }^{63}$ BrantT (2010), pp. 173-202.

${ }^{64}$ Como es sabido, la doctrina nacional no está conteste respecto de la calificación que corresponde a la obligación de entregar, sosteniéndose por algunos que se trata de una obligación de dar. MEza (2007), pp. 16-17. En el mismo sentido, Alessandri (1998), pp. 24-25; Court y Wegner (2013), p. 34; Abeliuk (2014), pp. 442-443. Mientras que, para otros, se trata de una obligación de hacer. Alessandri et al. (2016), pp. 156-157. En el mismo sentido, Ruz (2011), p. 82. En tanto, hay quienes han señalado que se trata de una obligación de hacer, a la cual se aplica el estatuto jurídico de las obligaciones de dar. RAmos (2008), p. 45. Finalmente, hay quienes han sostenido que puede ser de dar o de hacer, dependiendo de la naturaleza del título que justifica la entrega: si es translaticio, la obligación de entregar será de dar; si es de mera tenencia, será de hacer. En este sentido, Daniel Peñailillo sostiene que la obligación de entregar está asimilada a la de dar, cuando la entrega deriva o es consecuencia de una obligación de dar, en cambio, cuando surge autónomamente, es de hacer. Peñallillo (2003), p. 199.

${ }^{65}$ Court y Wegner (2013), p. 39.

${ }^{66}$ Alessandri et al. (2016), p. 162. En el mismo sentido, Ruz (2011), p. 86. Para René Ramos, tanto la obligación de dar, como la de entregar, pueden ser clasificadas en genéricas o específicas. Ramos (2008), p. 42.

${ }^{67}$ Álvaro Vidal explica: "las obligaciones con objeto fungible envuelven a las de dar genéricas y a las de hacer no personalísimas o fungibles”. VIDAL (2014), p. 143. 
genérica o específica, atendiendo a la naturaleza del objeto transportado, lo que dependerá de la naturaleza de la cosa entregada por el cargador al transportista para su transporte. Para estos efectos, resulta de interés distinguir si el contrato se ha celebrado bajo modalidad "FCL/FCL" o "LCL/LCL".

Cuando el contrato de transporte marítimo se ha celebrado bajo modalidad "FCL/FCL", esto significa que el transportista ha recibido un contenedor cerrado y sellado, en que tanto la estiba de la mercancía al interior del contenedor como el cerrado y el sellado del mismo han sido efectuados por el cargador ${ }^{68}$. Como consecuencia de ello, en el conocimiento de embarque se identifica el o los contendores por su número de serie, por lo que es posible entender que se trata de una especie o cuerpo cierto, ya que el o los contendores debidos se encuentran identificados de forma cabal, de manera que no cabe confundirlos con otros contenedores que presenten las mismas características. En consecuencia, en estos casos, el incumplimiento se verificará cuando el o los contenedores no lleguen a destino o lleguen con abolladuras o sufran otro tipo de mermas. Empero, cabe tener presente que, en este caso, es importante determinar quién ha proporcionado el contenedor, pues si fue proporcionado por el propio transportista, las simples abolladuras o mermas que experimente no constituirían inejecución contractual.

En cambio, si el contrato se celebró bajo la modalidad "LCL/LCL", esto significa que el transportista recibió mercadería aislada, de manera que tanto la estiba de la misma dentro del contenedor como su cerrado y sellado, han sido efectuados por el propio transportista. En consecuencia, la obligación de entrega puede ser tanto de especie o cuerpo cierto como de género, dependiendo de la naturaleza de la mercancía que el cargador haya entregado al transportista. Será de especie o cuerpo cierto si las cosas entregadas al transportista están perfectamente individualizadas, por ejemplo, electrodomésticos identificados por su número de serie; será de género si las cosas entregadas al transportista no están individualizadas de manera completa, como ocurre con el transporte de fruta. Si se trata de una especie o cuerpo cierto, se entenderá que hay incumplimiento

${ }^{68}$ La Corte de Apelaciones de Valparaíso, en una sentencia de 3 de octubre de 2011, rol n. ${ }^{\circ}$ 647-2011, caratulados "Mapfre Compañía de Seguros Generales S.A. c/ CSAV", estableció, en el considerando cuarto, que la modalidad de transporte FCL significa: "carga de contenedor completo, por lo que es el embarcador o su agente quienes proceden al llenado del contenedor y luego proceden a su sellado, de modo tal que la estiba al interior del contenedor no tiene responsabilidad el transportista, quien recibe un contendedor sellado y debe entregarlo en destino, lo que ocurrió, pues de los antecedentes no se consignan que hayan existido problemas durante el desarrollo del viaje o que el contenedor registre daños debido a su mala estiba dentro del barco, no registrando abolladuras ni otros daños visibles". 
cuando las especies no lleguen a destino o, bien, solo lleguen algunas o, bien, si las que llegan están rotas, destruidas o no funcionan. En cambio, si se trata de cosas genéricas, habrá incumplimiento cuando las cosas no lleguen a destino o, bien, cuando haya llegado una cantidad inferior a la embarcada o, bien, si ha sufrido algún otro tipo de daño (por ejemplo, si el combustible transportado se ha mezclado con agua o si el trigo transportado se pudrió).

Como podrá advertirse, tanto si el contenedor se ha embarcado bajo modalidad "FCL/FCL" como si se ha hecho bajo modalidad "LCL/LCL" y se trata de especies o cuerpos ciertos, se estará frente a una obligación de especie o cuerpo cierto o, como señala Álvaro Vidal, de una obligación de objeto no fungible, en las que el deudor compromete una determinada actividad, de manera que sobre él recaen unos deberes de conducta bastante delimitados y acotados ${ }^{69}$.

Tratándose de la entrega de una especie o cuerpo cierto, se ha sostenido que, en rigor, en caso de pérdida, la extinción de la obligación se produce como consecuencia de la imposibilidad sobrevenida de la prestación no imputable al deudor ${ }^{70}$, la cual se construye a partir de dos supuestos: uno objetivo, la inviabilidad o imposibilidad en sentido estricto de cumplir la prestación ${ }^{71}$, y otro subjetivo, que es la inimputabilidad, y que está representada por el caso fortuito ${ }^{72}$. Solo reunidos ambos elementos se configura este modo de extinguir; en cambio, si el caso fortuito afecta el cumplimiento exacto y oportuno de una obligación, pero sin tornar irrealizable la prestación, no se produce tal extinción de la obligación, sino que el efecto del caso fortuito es otro: opera como causa de exoneración de responsabilidad, con incidencia exclusiva en el remedio indemnizatorio, pero sin afectar la subsistencia del vínculo obligacional ${ }^{73}$.

Como consecuencia de lo señalado, debe entenderse que si el transportista marítimo no ha cumplido con su obligación de entrega, porque la mercancía sufrió pérdidas, mermas o daños por caso fortuito, habrá que distinguir: si la pérdida es total, se configura la imposibilidad sobrevenida de la prestación no imputable al deudor, por lo que se extingue su obligación; si la pérdida es parcial o si la mercancía solo sufrió daños, el transportista deberá entregarla en el estado en que se encuentre, sin

${ }^{69}$ VIDAL (2007b), p. 44.

${ }^{70}$ BrantT (2010), p. 172.

${ }^{71}$ La inviabilidad se traduce en que no puede, de manera alguna ejecutarse la prestación; de ahí que se habla de irrealizabilidad de la prestación, entendiéndose que se producirá el efecto extintivo si la imposibilidad es objetiva, absoluta y permanente. BRANTT (2010) p. 177.

${ }^{72}$ Op. cit., p. 174.

${ }^{73}$ Op. cit., p. 187. 
tener que indemnizar los perjuicios sufridos por el consignatario ${ }^{74}$. Con todo, también es posible que el caso fortuito incida en la oportunidad de cumplimiento, es decir, que sin que la mercancía haya sufrido algún tipo de merma o daño, la entrega al consignatario fuese tardía y, en tal caso, de todas maneras operará el efecto exoneratorio del caso fortuito ${ }^{75}$, por lo que el consignatario no estará facultado para demandar la indemnización por el retardo en la entrega; sin perjuicio de la regla del art. 986 del $C$. de $C$., en cuya virtud se estima que si el retraso se extiende por más de sesenta días, debe entenderse que la mercancía se ha perdido de forma definitiva, lo que implicaría que ya no cabe exigir el cumplimiento, por haber operado la imposibilidad sobrevenida de la prestación no imputable al deudor.

Por el contrario, cuando se ha embarcado un contenedor bajo modalidad "LCL/LCL" y se trata de cosas genéricas, se estará frente a una obligación de género o, como denomina Álvaro Vidal, de una obligación de objeto fungible. Como consecuencia de lo anterior, conforme explica el autor recién citado, el deudor se obliga a desplegar toda la actividad que sea necesaria para alcanzar el fin último del contrato, lo que se traduce en que las posibilidades de cumplimiento sean más amplias que en las obligaciones de objeto no fungible ${ }^{76}$.

Dado que en las obligaciones genéricas, como señala el art. 1509 de Código Civil chileno, el deudor queda libre entregando cualquier individuo del género con tal que sea de una calidad a lo menos mediana, si la cosa transportada sufrió pérdidas, mermas o daños, no se extingue la obligación, porque el género no perece, conforme lo expresa el art. 1510 del mismo cuerpo legal. En esta hipótesis, el efecto del caso fortuito es la exención de la indemnización de perjuicios, es decir, se exonera de responsabilidad al transportista ${ }^{77}$. Como explica María Graciela Brantt, ha sido un error de la doctrina tradicional identificar caso fortuito con extinción de la obligación, pues aquel puede solo impedir el cumplimiento oportuno o perfecto de la obligación y, en tal caso, una vez desaparecido el obstáculo, el deudor de todas maneras debe cumplir, satisfaciendo el interés del acreedor: si ha cesado el impedimento y siendo el interés del acreedor susceptible de satisfacción, no hay razón para sostener la extinción del vínculo obligacional. Como consecuencia de lo anterior, una vez

${ }^{74}$ Debe tenerse presente que, conforme a lo dispuesto en el art. 984 del C. de C., en orden a que la prueba liberatoria del transportista marítimo implica probar que él, sus agentes o dependientes adoptaron todas las medidas razonables para evitar la pérdida, daño o retraso.

${ }^{75}$ BRAntt (2010), p. 193.

${ }^{76}$ VIDAL (2007b), p. 44.

${ }^{77}$ BRANTT (2010), pp. 191-192. Debe tenerse presente, como se expresó, lo dispuesto en el art. 984 del C. de C. 
desaparecido el obstáculo, el deudor debe proceder al cumplimiento, sin que la existencia del vínculo obligatorio se haya visto afectada ${ }^{78}$, solo que ese deudor no estará obligado a indemnizar los perjuicios que el retardo haya causado al acreedor ${ }^{79}$.

Aplicando lo señalado al incumplimiento de la obligación de entrega por parte del transportista marítimo, se debiera entender que si las cosas genéricas han experimentado alguna pérdida, merma o daño, el transportista tendría que obtener otras tantas, del mismo género y calidad, para poder proceder al pago $^{80}$. Sin embargo, desde un punto de vista práctico, es probable que realizar una operación de tal envergadura implique demasiado tiempo, lo que podría frustrar el interés del acreedor, de manera que ese pago tardío no produciría el efecto de satisfacer tal interés.

Lo dicho no se contradice con las disposiciones del Código de Comercio, relativas a las "reservas" en el conocimiento de embarque. Como explica Claudio Barroilhet, se trata de las excepciones o delimitaciones a la regla del valor probatorio del conocimiento de embarque, pues, a través de la reserva, se restringe el alcance de la presunción de veracidad en orden a que las mercancías han sido entregadas en buen estado; en consecuencia, la presunción no alcanza a las reservas ${ }^{81}$.

De las distintas reservas reglamentadas en el art. 1017 del C. de C., interesa la que regula el numeral tercero de dicha disposición: el transportista marítimo puede estampar una reserva al conocimiento de embarque cuando no tenga los medios razonables para verificar la exactitud de los datos acerca de las mercancías que contenga el conocimiento de embarque $^{82}$.

A partir de lo dispuesto en el art. $1018 \mathrm{del} C$. de C., se ha sostenido que la reserva debe ser fundada en una de las causas que establece el art. $1017 \mathrm{del}$ $C$. de C., y que debe ser específica ${ }^{83}$. Eugenio Cornejo agrega que la doc-

${ }^{78}$ BRANTT (2010), pp. 192-193.

${ }^{79}$ Op. cit., pp. 201-202.

${ }^{80}$ En este sentido, cabe tener presente que el art. 984 del C. de C. señala que el transportador será responsable de los perjuicios resultantes de la pérdida o del daño de las mercancías, así como del retraso su entrega, lo que se entiende que se refiere a la responsabilidad en sentido estricto, o sea, al remedio indemnizatorio. Esta disposición agrega, a continuación, la posibilidad del transportista de exonerarse de responsabilidad acreditando el empleo de la debida diligencia. De esta manera, el empleo de la debida diligencia solo permite al transportista exonerarse de la indemnización de perjuicios, mas no de los demás remedios contractuales.

${ }^{81}$ Barroilhet (2014), p. 458.

${ }^{82}$ Op. cit., p. 459.

${ }^{83} \mathrm{Ibid}$. En el mismo sentido, Osvaldo Contreras exige, para la validez de una reserva, en este caso, que especifique la falta de medios razonables para verificar los datos que se estamparon en el conocimiento de embarque. CONTRERAS (2000), p. 245. También lo en- 
trina europea ha sostenido que las reservas deben corresponder a una objeción legítima, verdadera y fundamentada ${ }^{84}$.

Alejandro Díaz y Claudio Barroilhet añaden que se trata, en este caso, de una prueba negativa entregada a la discrecionalidad del juez, dado que el art. 1017 n. ${ }^{\circ} 3$ del C. de C. emplea la expresión 'razonables', de manera que corresponde a él calificar, en cada caso concreto, cuáles eran esos medios razonables y si el transportador debía o no tenerlos ${ }^{85}$.

Este tema resulta relevante, pues, como se advierte, podría pensarse que la sola incorporación de la expresión "FCL/FCL" a un conocimiento de embarque constituye una reserva en los términos exigidos en las disposiciones legales señaladas. Empero, ello no es así, porque la simple incorporación de dicha expresión no cumple con los requisitos que exige el art. 1017 del Código de Comercio para ser considerada como reserva, toda vez que no se han expresado los motivos razonables que no se ha tenido para verificar la exactitud de los datos acerca de las mercancías que contenga el conocimiento de embarque.

Cabe tener presente que el tema de las reservas debe examinarse en el contexto de la mercancía recibida por el transportista de parte del cargador: si se ha recibido un contenedor bajo modalidad "FCL/FCL", las reservas deberán entenderse referidas a la carga efectivamente entregada por el cargador y recibida por el transportista, esto es, el contenedor; en cambio, si se ha recibido un contenedor bajo modalidad "LCL/LCL", las reservas -que también deben entenderse referidas a la mercancía efectivamente entregada por el cargador y recibida por el transportista- tendrán relación con los objetos individuales que han sido recibidos y entregados para la carga y estiba por parte del transportista ${ }^{86}$.

tiende así Félix García, para quien carece de validez una cláusula genérica. GARCíA (1993), p. 287.

${ }^{84}$ Cornejo (2003), p. 267.

${ }^{85}$ Barroilhet y Díaz (2002), p. 225. Estos autores agregan que el juez debe considerar, entre otros factores, el tipo de mercancía de que se trate, la unidad de transporte, quién consolida y sella dicha unidad de transporte, etcétera.

${ }^{86}$ Como se ha planteado por la doctrina, este tema es de un aspecto crucial en el transporte, ya que, en la reglamentación legal de las reservas, puede advertirse la conver-gencia de dos intereses. BARROILHET y DíAz (2002), p. 226: por una parte, está el interés del transportista marítimo, para quien, atendida la velocidad de la actividad marítima, no resulta razonable exigirle que revise de manera minuciosa toda la mercancía, con el objeto de poder constatar su verdadero estado y así confeccionar de manera precisa el conocimiento de embarque; ello resulta menos razonable cuando la mercancía ha sido estibada por el cargador, quien entrega al transportista un contendor cerrado y sellado. Pero, por otro lado, existe una presunción de veracidad que rodea al conocimiento de embarque y que es la base del régimen de responsabilidad del transportista, de manera que las reservas que formule pueden hacer inaplicable la presunción de haber recibido las mercancías en buen estado, debiendo ser fundadas. Tomasello (2014), p. 519. A juicio de Claudio Barroilhet y Alejandro 
b.4 Atraso, que es la entrega de la carga fuera del plazo previamente acordado y si no hay plazo convenido, en el tiempo en que sería razonable exigir la entrega a un transportador diligente

Para el Claudio Barroilhet equivale al cumplimiento tardío de la obligación de transportar ${ }^{87}$, es decir, un retraso en la entrega ${ }^{88}$.

Como consecuencia de ello, corresponde al juez determinar si hubo o no atraso, para lo cual deberá comparar la actitud que asumió el transportador y la que habría asumido un transportador diligente ${ }^{89}$.

Cabe recordar que si transcurren sesenta días con posterioridad a la expiración del plazo de entrega antes referido, el legislador entiende que las mercancías se han perdido, aunque físicamente no hubiese sido así, con lo cual lo que califica como indemnización moratoria se agregará a una compensatoria $^{90}$.

\section{c) Obligaciones del consignatario}

El art. 974 n. ${ }^{\circ} 4 C$. de C. señala que el consignatario "es la persona habilitada por un título para recibir las mercancías". Como señala Claudio Barroilhet, ese título, por regla general, será el conocimiento de embarque ${ }^{91}$.

Pese a que el consignatario no es parte del contrato de transporte marítimo ${ }^{92}$, de todas formas corresponde a un sujeto que tiene interés en la expedición marítima o, como dice Claudio Barroilhet, es parte de la operación de transporte en la que se ejecuta el contrato y, como tal, adquiere los derechos y obligaciones que derivan del mismo ${ }^{93}$. Esta situación ha sido explicada de manera tradicional por la doctrina, recurriendo a la figura de la estipulación a favor de otro $^{94}(\text { art. } 1449 \mathrm{del} C C)^{95}$.

Díaz, ambos intereses se concilian al tener presente que el incumplimiento de la obligación de veracidad por parte del cargador no lo libera de su deber de entregar las mercancías según reza el conocimiento de embarque. Barroilhet y Díaz (2002), p. 227, idea que es complementada por Claudio Barroilhet, al sostener que la ley, al exigir la descripción de las mercancías y la comprobación del estado en que fueron recibidas por el transportista, solo se refiere al estado aparente o externo de las mismas. BARROILHET (2014), p. 460.

${ }^{87}$ Barroilhet (2014), p. 475.

${ }^{88}$ Tomasello (2014), p. 472.

${ }^{89}$ Barroilhet y Díaz (2002), p. 246.

${ }^{90}$ Tomasello (2014), p. 473.

${ }^{91}$ Barroilhet (2014), p. 427.

${ }^{92}$ Claudio Barroilhet advierte que el consentimiento del consignatario no es requerido para el perfeccionamiento del contrato de transporte, razón por la cual no puede ser considerado como parte del mismo. BARrollhet (2014), p. 427.

${ }^{93}$ Op. cit., p. 428.

${ }^{94}$ Ibid.

${ }^{95}$ Conviene advertir que esta forma de explicar el contrato de transporte marítimo bajo régimen de conocimiento de embarque solo resulta aplicable cuando cargador y 
Como consecuencia de lo anterior, surgen derechos y obligaciones para el consignatario, con tal que haya aceptado expresa o tácitamente. Dentro de los derechos, es posible encontrar la facultad de reclamar las mercancías. Dentro de las obligaciones, se puede identificar:

\section{c.1 Recibir la mercancía ${ }^{96}$}

El consignatario no solo tiene el derecho a reclamar las mercancías, sino que, además, tiene la obligación de recibirlas.

Según Claudio Barroilhet, esta obligación no se encuentra señalada por la ley de forma explícita, pero entiende que se está implícita en ella, pues se desprende del derecho del transportista a entregar las mercancías para poder liberarse de sus obligaciones de transporte y custodia, lo que implica que, de manera correlativa, existe una obligación para el consignatario de recibir dichas mercancías. En otras palabras, la entrega de las mercancías es, jurídicamente, un pago y, por lo mismo, el consignatario, que es el acreedor, debe permitir al transportista que le pague ${ }^{97}$.

El Código de Comercio no contiene reglas especiales en torno a los casos en que se produce su incumplimiento, por lo que, aplicando las reglas generales del art. 1556 del Código Civil, debe entender que el consignatario no cumple cuando no recibe la totalidad de las mercancías, cuando solo recibe una parte de las mercancías que debe retirar o cuando las recibede forma tardía.

c.2) Pagar el flete, cuando sea procedente

A partir de lo dispuesto en el art. 1021 n. ${ }^{\circ} 4$ y 5 del $C$. de $C$., se desprende que, por regla general, esta obligación recae sobre el cargador, a menos que se haya estipulado que el flete será pagado por el consignatario y esto conste en el respectivo conocimiento de embarque ${ }^{98}$.

En esta materia, el Código de Comercio no establece disposiciones especiales, por lo que, aplicando las reglas generales establecidas en el art.

consignatario son sujetos distintos. Sin embargo, dependiendo de la forma como haya sido pactado (por aplicación de los INCOTERMS), puede ocurrir que cargador y consignatario sean un mismo sujeto, como ocurre, por ejemplo, con los INCOTERMS EXW, FAS y FOB, ya que, en todos estos casos, el transporte es contratado por el propio comprador en una compraventa internacional; como consecuencia de ello, dicho comprador será simultáneamente cargador y el consignatario. Tomasello (2014), pp. 632-634. Este caso no será analizado en este trabajo por razones de espacio, sin perjuicio de dejar su estudio para una próxima investigación. En consecuencia, el análisis que sigue discurrirá sobre la base de la participación de tres sujetos distintos en la operación de transporte marítimo.

${ }^{96}$ Barroilhet (2014), p. 487.

${ }^{97}$ Ibid.

${ }_{98}$ Op. cit., p. 488. 
1556 del $C C$, debe entenderse que habrá incumplimiento del consignatario cuando no pague la totalidad del flete (estando obligado a hacerlo), o pague solo una parte o lo haga de manera tardía.

\section{LOS REMEDIOS CONTRACTUALES EN EL CONTRATO DE TRANSPORTE MARÍTIMO BAJO RÉGIMEN DE CONOCIMIENTO DE EMBARQUE}

Un primer aspecto que se debe destacar es la autonomía en los remedios contractuales; en efecto, conforme lo ha reconocido la doctrina más especializada, la tendencia contemporánea es que el acreedor tenga libertad para optar por aquel que mejor satisfaga su interés, con tal que se cumpla con los requisitos propios del mismo. Como explica Álvaro Vidal, el énfasis de los remedios contractuales está puesto en la satisfacción del interés del acreedor y no en la sanción al deudor incumplidor; para tales efectos, la ley o el contrato pone a disposición del acreedor un conjunto de medidas entre las que puede optar de forma más o menos libremente, para la realización de su interés en la prestación afectada ${ }^{99}$. Y más adelante insiste en que cualquiera que sea la clase de obligación de que se trate, el solo incumplimiento abrirá para el acreedor un abanico de remedios, incluida la indemnización de perjuicios, entre los cuales el acreedor puede optar de forma libre, si es que concurre el respectivo supuesto de hecho ${ }^{100}$. Así lo entiende también Carlos Pizarro, para quien el ordenamiento jurídico pone a disposición del acreedor insatisfecho un abanico de remedios para la protección de su interés afectado, perteneciendo la opción al acreedor, quien la ejercerá según lo estime conveniente en orden a satisfacer su interés ${ }^{101}$.

Esta posibilidad que tiene el acreedor para optar entre los distintos remedios contractuales resulta tan evidente, que Patricia López la cataloga como un verdadero derecho de opción del acreedor para escoger entre ellos, subordinado -empero- a diferentes factores, como la entidad del incumplimiento, la situación económica del acreedor al producirse dicho incumplimiento y el carácter relacional o colaborativo del contrato ${ }^{102}$.

A partir de lo expuesto, es posible advertir que, desde la perspectiva del nuevo derecho de la contratación, se presentan importantes cambios en relación con la perspectiva tradicional de analizar el contrato de transporte marítimo bajo el régimen de conocimiento de embarque, en lo

\footnotetext{
${ }^{99}$ VIDAL (2007a), pp. 517-518.

${ }^{100}$ Op. cit., p. 527. En el mismo sentido LóPez (2010), p. 88 y Prado (2015a), p. 22.

${ }^{101}$ Pizarro (2008a), p. 400.

${ }^{102}$ LÓPEZ (2015), pp. 107-108.
} 
que tiene relación con la forma cómo se coordinan los distintos remedios contractuales.

\section{Los remedios frente al incumplimiento del transportista marítimo}

En concepto de Claudio Barroilhet y Alejandro Díaz, este régimen no es muy diferente del sistema común de responsabilidad, pues sostienen que el transportista, en definitiva, responde del incumplimiento total, parcial y cumplimiento tardío en su obligación de transportar y custodiar las mercancías $^{103}$. Como consecuencia de lo anterior, Leslie Tomasello sostiene que, si se hace una comparación con el derecho común, es posible sostener que la indemnización, en el caso de pérdida o daño, tendrá carácter compensatorio, pues reemplazará total o parcialmente el objeto de la obligación, al tiempo que en el evento del retardo será moratoria ${ }^{104}$.

Además de lo señalado, se trataría de un régimen de responsabilidad subjetiva, con culpa presumida ${ }^{105,106}$, ya que la fuente de la responsabilidad está en no haber empleado, en el cumplimiento de la obligación, el grado de diligencia y cuidado que, según el tipo de contrato, estaba asignado en las leyes matrices ${ }^{107}$. Siendo un contrato oneroso, la debida diligencia que debe emplearse es la de un buen y leal comerciante, esto es, la diligencia de un buen padre de familia asignada a una actividad comercial específica ${ }^{108}$.

Consecuente con lo anterior, Félix García sostiene que esta presunción de culpabilidad del transportista marítimo incluye la denominada "culpa náutica", que es aquella responsabilidad que nace de daños emanados por errores o culpabilidad causados por la dotación de la nave en la conducción de la misma y de la cual tradicionalmente estuvo exonerado el armador ${ }^{109}$.

${ }^{103}$ Barroilhet y Díaz (2002), p. 234.

${ }^{104}$ Tomasello (2014), p. 472.

${ }^{105}$ Barroilhet (2014), p. 480. En el mismo sentido, Contreras (2000), p. 259.

${ }^{106}$ Cabe observar que Claudio Barroilhet y Alejandro Díaz advierten que existiría una opinión que sostiene que la responsabilidad del transportista sería objetiva, pues se configura cuando hay un contrato de transporte marítimo, incumplimiento del portador, daño y relación de causalidad entre el incumplimiento y el daño. Barroilhet y DíAz (2002), p. 251. Esta forma de razonar es difícil de sostener, pues, en caso de tratarse de un caso de responsabilidad estricta, no se podría justificar el empleo de la debida diligencia como causal de exoneración de responsabilidad, como sí la contempla el art. 984 del Código de Comercio.

${ }^{107}$ Cornejo (2003), p. 242.

${ }^{108} \mathrm{Ibid}$. En términos de Claudio Barroilhet, el transportista es responsable de la culpa leve. Barroilhet (2014), p. 480. En el mismo sentido, Tomasello (2014), p. 476.

${ }^{109}$ García (1993), p. 271. 
Claudio Barroilhet agrega que se trata de un sistema de culpa presumida $^{110}$, pues se admite la prueba liberatoria del transportista. En efecto, este puede destruir la presunción de culpa y, por ende, puede exonerarse de responsabilidad si prueba que él, sus agentes o dependientes adoptaron todas las medidas razonables para evitar la pérdida, daño o retraso ${ }^{111}$. Agrega Félix García que la razonabilidad de las medidas adoptadas será un factor que deberá ponderar el juez que conozca del diferendo, sea por la vía judicial o por la vía arbitral ${ }^{112}$.

Desde esta perspectiva, Claudio Barroilhet critica la reglamentación que ha hecho el legislador de la responsabilidad del transportista marítimo. En efecto, sostiene que la exención de responsabilidad mediante la prueba de la debida diligencia desvirtúa la naturaleza de obligación de resultado, como lo es la obligación del transportista de conducir las mercancías de un puerto a otro, y es algo que llama la atención, pues en estas no se admite al deudor eximirse de responsabilidad probando que ha empleado la diligencia y el cuidado debidos. En consecuencia, a su juicio, se trata de una obligación de resultado, pero con una responsabilidad que es propia de las obligaciones de medio ${ }^{113}$.

Esta opinión de Caludio Barroilhet podría verse reforzada por la opinión expresada por Carlos Pizarro, a la hora de examinar la distinción entre obligaciones de medios y de resultado. En efecto, Carlos Pizarro plantea que, en las obligaciones de medios, no es posible diferenciar el incumplimiento de la culpa, toda vez que la noción misma de cumplimiento se encuentra integrada por la noción de diligencia, ya que, en estas obligaciones, el deudor se ha obligado a actuar de una forma diligente. En cambio, en las obligaciones de resultado, la noción de culpa no cumple ninguna función,

${ }^{110}$ Barroilhet (2014), p. 480.

${ }^{111}$ Op. cit., p. 469. En el mismo sentido, Tomasello (2014), p. 474.

${ }^{112}$ García (1993), p. 271.

113 Barroilhet (2014), p. 481. En el mismo orden de cosas, Leslie Tomasello critica a quienes han sostenido que se trata de una responsabilidad objetiva. En efecto, discrepa de este planteamiento sosteniendo: "está en abierta contradicción con el artículo 984 que claramente conduce a inferir que el régimen es de responsabilidad subjetiva, precisamente porque para exonerarse de la culpa presumida el transportador debe producir la prueba que allí se menciona, sino porque, si alguna duda quedare, como se encargaron de esclarecerlo las propias Reglas de Hamburgo en su Anexo II 'Consenso de la Conferencia de las Naciones Unidas sobre el Transporte Marítimo de Mercancías', ...queda entendido que la responsabilidad del porteador en virtud del presente Convenido se basa en el principio de la presunción de culpa o negligencia. Esto significa que, por regla general, la carga de la prueba recae en el porteador, pero que, en ciertos casos, las disposiciones del Convenio modifican esta regla. Obviamente que está aludiendo a la presunción de culpa, que es la regla general, y a aquellos casos excepcionalmente en que las Reglas de Hamburgo alteran la regla general”. TOMASELLO (2014), pp. 474-475. 
pues lo relevante es si se logró o no el resultado, sin que interese el comportamiento del deudor. Como consecuencia de esto -sostiene Carlos Pizarroel hecho de calificar a una obligación como de resultado implica instaurar una verdadera responsabilidad objetiva en materia contractual ${ }^{114,115}$.

Debe advertirse que esta forma de razonar resulta bastante discutible, pues, por una parte, la distinción entre obligaciones de medios y de resultado no tiene una relación necesaria con el tipo de responsabilidad contractual -objetiva o subjetiva- que se pueda generar por el incumplimiento ${ }^{116}$; en efecto, la distinción entre obligaciones de medios y de resultado se formula a partir de la manera cómo se satisface el interés del acreedor y, cómo se entiende que la noción de incumplimiento es objetiva y abstracta, dicha noción se separa de la idea de imputabilidad. Por otro lado, el planteamiento que formula Carlos Pizarro debe ser entendido desde la perspectiva del incumplimiento contractual; en efecto, en las obligaciones de medios un comportamiento culpable constituye inejecución, pues el deudor se ha obligado a actuar de manera diligente; mientras que, en las obligaciones de resultado, un comportamiento culpable no constituye incumplimiento, pues el deudor no se ha obligado a actuar de forma diligente, y solo habrá inejecución del contrato si el deudor no alcanza el resultado comprometido.

Luego, la forma de razonar de Claudio Barroilhet parece confundir lo que es el cumplimiento con lo que es el empleo de la debida diligencia, esto es, lo que la doctrina tradicional ha sostenido al exigir que dentro de la noción de incumplimiento se incluya la imputabilidad del deudor, pues solo si se considera que la idea de imputabilidad forma parte del incumplimiento, resulta un contrasentido sostener que la prueba de la debida diligencia pueda exonerar de responsabilidad al deudor en una obligación de resultado; pero si se considera -como hace la doctrina contemporá-

${ }^{114}$ Pizarro (2008b), p. 263.

${ }^{115}$ En nuestro concepto, no cabría identificar obligación de medios con responsabilidad subjetiva y obligación de resultado con responsabilidad objetiva. En este sentido, Daniel Peñailillo, independientemente del tipo de obligación de que se trate, plantea que la responsabilidad contractual en el Código Civil siempre sería objetiva. En efecto, ha señalado, además, que las disposiciones que regulan la indemnización de perjuicios contractuales son, básicamente, los arts. 1556, 1557, 1558 y 1559 del $C C$, ninguno de los cuales menciona a la culpa como fundamento o elemento de la responsabilidad contractual, ni a la ausencia de ella como el límite de tal responsabilidad, a partir del cual el deudor quedaría liberado. En consecuencia, en su concepto, las reglas que regulan la indemnización de perjuicios contractuales exigen: incumplimiento (arts. 1556 y 1558 del CC); daño (arts. 1556 y 1558 del $C C$ ), mora (art. 1557 del $C C$ ) y causalidad (art. 1558 del $C C$ ). De esta manera no se ha exigido culpa ni se ha dispuesto que la ausencia de ella libere al deudor en caso de inejecución. PeÑaIliLlo (2009), pp. 338-340.

${ }^{116}$ Lobato (1992), pp. 722-723. 
nea- que la noción de incumplimiento es objetiva, resulta perfectamente posible concebir que la prueba de la debida diligencia pueda exonerar de responsabilidad, toda vez que -no obstante haber inejecución de la obligación- se excluye la imputabilidad.

Por su parte, Claudio Barroilhet sostiene que el transportista también puede limitar su responsabilidad, así como la de sus agentes y dependientes, a un monto preestablecido por la ley ${ }^{117}$.

En caso de incumplimiento de sus obligaciones por parte del transportista marítimo, cabe preguntarse cuáles son los daños indemnizables. Claudio Barroilhet y Alejandro Díaz sostienen que es posible identificar dos opiniones ${ }^{118}$ :

a) Una primera respuesta es sostener que solo se indemnizan los perjuicios que provengan de manera directa de la pérdida o daño en la mercancía, esto es, solo se indemniza el daño emergente y no el lucro cesante.

Para justificar esta opinión se ha señalado que la ley expresa que el transportista responde por la pérdida, daño o retraso; que esta responsabilidad es limitada y que esa limitación se aplica a la pérdida, daño o retraso; es decir, si el transportista tiene una obligación de resultado solo es responsable por los perjuicios directos y previstos que la pérdida o daño irrogan y ellos solo corresponden al daño emergente, cuando se trata de la indemnización compensatoria. En cambio, la indemnización moratoria sí admitiría la reparación del lucro cesante.

b) Otra opinión señala que la indemnización comprende tanto el daño emergente como el lucro cesante.

Se argumenta señalando que, en el Código de Comercio, no existe una regla especial que se refiera a los daños que deben ser indemnizados y, por lo mismo, se aplica la regla general del art. 1556 del $C C$. Esta disposición establece que no se indemniza el lucro cesante cuando la ley de forma expresa limita la indemnización al daño emergente, cosa que no ocurre en la especie. En este sentido, el lucro cesante no es un daño imprevisto ni indirecto y, por lo mismo, queda comprendido dentro de los rubros a indemnizar.

Por otro lado, interesa determinar cómo entran a coordinarse los distintos remedios contractuales. En efecto, como ya se ha señalado, el denominado nuevo derecho de la contratación entiende que el acreedor puede optar libremente entre los distintos remedios contractuales, con tal que concurran los supuestos propios del mismo. Desde esta perspectiva,

\footnotetext{
${ }^{117}$ Barroilhet (2014), p. 469.

${ }^{118}$ Barroilhet y Díaz (2002), pp. 247-251.
} 
puede advertirse que la doctrina tradicional ha puesto el énfasis en la indemnización de perjuicios, pues esta se encuentra reglamentada con algún grado de detalle por el Código de Comercio, pero ello no implica que el acreedor de la respectiva obligación quede privado de los demás remedios. De esta manera, el consignatario cuya mercancía no ha llegado o ha llegado dañada, también podría instar por otro remedio contractual, por ejemplo, la sustitución de las mercancías, la rebaja del precio o la suspensión del cumplimiento de la propia obligación, si el pago del flete fuere de cargo suyo.

Ahora bien, por las características propias del comercio en general y del comercio marítimo en particular, en la práctica, lo más probable es que el cumplimiento de los plazos de entrega de las mercancías sea un elemento esencial, por lo que el remedio indemnizatorio tiende a ser el que mejor satisface el interés del acreedor. De ahí que la indemnización de perjuicios haya sido reglamentada de manera minuciosa por el legislador de la Ley n. ${ }^{\circ} 18680$, y que no existan dudas en torno a que este remedio pueda ejercerse de manera autónoma. Empero, puede estimarse que hay otros remedios contractuales que pueden ser concurrentes con la pretensión indemnizatoria; esto es lo que ocurriría, por ejemplo, con la rebaja del precio, que se considera como un remedio contractual de aplicación general ${ }^{119} \mathrm{y}$, en este contexto, puede estimarse que, en el caso de mercancías perdidas o dañadas, sea total o parcialmente, quien hubiere pagado el flete -cargador o consignatario- podría hacer uso del mismo. Cabe tener presente que la rebaja del precio, como remedio contractual, solo exige como presupuesto el incumplimiento del deudor ${ }^{120}$, por lo que el tema de la culpa o la entidad o magnitud del incumplimiento son ajenos al mismo. Este tema cobra importancia cuando es el consignatario quien paga el flete, ya que, además de demandar la correspondiente indemnización de perjuicios, podría demandar la rebaja del precio.

\section{Los remedios frente al incumplimiento del cargador}

a) No pago del flete

Cabe tener presente que, según el art. 1021 del Código de Comercio, el flete se gana por parte del transportista y, por lo mismo, se hace exigible, una

${ }^{119}$ Prado (2015b), p. 618. Esta recepción amplia de la rebaja del precio como remedio contractual ha llevado a Francisca Barrientos a entender que también tiene cabida en el ámbito del consumo. Barrientos (2014), p. 71. Un estudio más profundo de la amplia recepción de la rebaja del precio como remedio contractual se puede ver en PrADo (2013), pp. 369-383.

${ }^{120}$ Morales (2006), pp. 31-32. 
vez que haga entrega de las mercancías en el punto de destino consignado en el contrato. Para estos efectos, la entrega debe hacerse bajo alguna de las modalidades señaladas en el art. 983 del referido Código, mediando, además, la documentación respectiva. Como consecuencia de lo anterior, el flete no se gana por el simple arribo de la nave, sino que se necesita de la entrega de las mercancías ${ }^{121}$.

A partir de lo señalado, debe tenerse presente que puede ocurrir que el conocimiento de embarque nada diga respecto del pago del flete; en tal caso, se entiende que el flete debe ser pagado por el cargador. Pero, considerando la disposición legal citada, el transportista solo tendrá derecho a cobrarlo una vez que las mercancías sean entregadas al consignatario, en los términos señalados en el art. 983 de referido cuerpo legal. Acontecido lo anterior, puede ocurrir que el cargador no pague el flete al transportista y, por lo mismo, este no pueda hacer uso del derecho legal de retención que establece el art. 865 del mismo Código. Frente a este escenario, el Código de Comercio no establece reglas especiales en materia de remedios contractuales, de manera que cabrá aplicar las reglas generales en caso de inejecución contractual.

Debe advertirse que hay remedios que, por su propia naturaleza, no servirían para satisfacer el interés del acreedor en este caso de incumplimiento, por ejemplo, la rebaja del precio, la sustitución de las mercancías o la resolución del contrato, de manera que solo tendrían cabida la pretensión de cumplimiento específico y la indemnización de perjuicios.

b) Falta de entrega de las mercancías

El Código de Comercio no prevé algún remedio contractual en especial para el caso que el cargador no entregue la mercancía al transportista marítimo, por lo que cabe aplicar las reglas generales del derecho común en materia de remedios contractuales.

Sin perjuicio de lo expuesto, desde un punto de vista práctico, podría ocurrir que el cargador no entregue al transportista toda la mercancía que aquel ha comprometido enviar al consignatario; des posible, en tal caso, hablar de incumplimiento del porteador marítimo? Todo indica que no, pues el transportista solo se obliga a conducir la mercancía que el cargador le ha entregado para tal efecto, siendo inoponible el contrato que pueda existir entre cargador y consignatario (una compraventa, como es el caso habitual).

Como consecuencia de lo señalado, se estaría frente al incumplimiento de una obligación secundaria del cargador cuya infracción da lugar a la correspondiente indemnización de perjuicios, si concurren todos los demás requisitos para que ella sea procedente.

${ }^{121}$ García (1993), p. 294. 
c) Falta de entrega de la documentación y antecedentes necesarios para llevar el transporte a buen éxito

El Código de Comercio no prevé algún remedio contractual especial para el caso que el cargador no entregue la documentación y antecedentes necesarios para llevar el transporte a buen éxito, o si los entregados no son íntegros, completos o fidedignos, por lo que cabría aplicar las reglas generales en materia de remedios contractuales establecidas por el Código Civil.

Sin perjuicio de lo expresado, ha de entenderse que, en este caso, la aplicación de algunos remedios contractuales debieran adecuarse a la especial relación obligatoria de que se trata. De esta manera, se entiende que la sustitución de las mercancías debiera traducirse en la sustitución de la documentación y antecedentes entregados por otros que sean necesarios para conducir con éxito las mercancías recibidas por el porteador; mientras que la rebaja del precio debiera traducirse en disminuir la mercancía a conducir, restringiéndola a aquella que puede ser transportada sin inconvenientes, por contar el transportista con la documentación y antecedentes necesarios.

d) Incumplimiento de la obligación de describir fidedignamente la mercancía que embarca

$\mathrm{El}$ art. 1022 del C. de C. establece el remedio indemnizatorio, al señalar que, en caso de inexactitud de estos datos, el cargador deberá indemnizar al transportista de los perjuicios que de ello resulten. La misma disposición agrega que el derecho del porteador a reclamar la indemnización no limitará la responsabilidad del transportista frente a una persona distinta del cargador, es decir, el deber de describir fidedignamente la mercancía solo se da entre cargador y transportista, de manera que no altera la obligación de este, de entregar la mercancía al consignatario tal como aparece descrita en el conocimiento de embarque ${ }^{122}$.

Sin embargo, es dable estimar que también pueden tener cabida otros remedios contractuales, pero con la necesaria adecuación. De esta manera, la sustitución de la mercancía podría traducirse en la sustitución del documento que da cuenta de la misma entregada al porteador por otro que sí diera cuenta de manera fidedigna de la mercancía que se le entregó o, bien, la rebaja del precio se traduciría en conducir solo aquella mercancía fidedignamente descrita por el cargador.

${ }^{122}$ Barroilhet (2014,) p. 461. 
e) Incumplimiento de la obligación de indicar

la peligrosidad de la mercancía que embarca

El art. 1013 del C. de C. contempla dos remedios en caso de inejecución:

e.1 El cargador será responsable frente al transportista (documental y efectivo, en su caso), de los perjuicios resultantes del embarque de tales mercancías, es decir, procede la indemnización de perjuicios.

e.2 Las mercancías podrán, en cualquier momento, ser descargadas, destruidas o transformadas en inofensivas, según requieran las circunstancias, sin que haya lugar a indemnización.

En relación con estos dos remedios, cabe tener presente:

e.1 Son copulativos, es decir, la descarga de las mercancías no excluye la posibilidad de demandar la correspondiente indemnización. Así se desprende del empleo de la conjunción 'y' que utiliza esta disposición.

e.2 No operan si el transportista tuvo conocimiento del carácter peligroso de las mercancías, aun cuando haya tomado conocimiento de su peligrosidad por otro conducto, toda vez que dicho conocimiento convalida la omisión del cargador ${ }^{123}$.

e.3 La convalidación por conocimiento a que se ha hecho referencia en el acápite anterior no opera si las mercancías son realmente peligrosas para la vida humana o los bienes; en tal caso las mercancías pueden ser descargadas, destruidas o transformadas en inofensivas, sin que haya lugar a indemnización, salvo la obligación de contribuir a la avería gruesa o la responsabilidad del transportista, de conformidad con lo dispuesto en los arts. 984 a 991 del Código de Comercio.

Según Claudio Barroilhet, las mercancías son realmente peligrosas cuando se trata de casos en que el peligro se ha activado o hecho efectivo, y pasa de ser una probabilidad a una amenaza inminente ${ }^{124}$.

Ha de estimarse que, por razones prácticas, no podrían tener cabida otros remedios como la rebaja del precio o la sustitución de las mercancías. Empero, si el transportista toma conocimiento de la peligrosidad de las mercancías antes del embarque, podría tener lugar la suspensión de la propia obligación por incumplimiento de la obligación de la contraparte $y$, en consecuencia, el transportista podría negarse a embarcar la mercancía peligrosa cuando no se ha dado cumplimiento a las obligaciones que impone el art. 1013 del Código de Comercio.

${ }^{123}$ Barroilhet (2014), p. 464.
${ }^{124}$ Op. cit., p. 465. 
f) Además, Claudio Barroilhet explica que, a partir de lo dispuesto en el art. 1012 del C. de C., el cargador, sus agentes o dependientes son responsables por ${ }^{125}$

f.1 Las pérdidas sufridas por el transportista documental o efectivo (en su caso), por ejemplo, si su mercancía está mal empacada o embalada y se derrama o filtra, contaminando otra carga, o si embarca mercancías ilegales en un contenedor que es decomisado por la autoridad de un país, retardando el zarpe del buque y confiscando el contenedor, etcétera.

f.2 El daño sufrido por la nave, por ejemplo, si la mercadería está mal embalada o empacada, se derrama y daña la nave.

Cabe tener presente que se ha sostenido que esta responsabilidad es subjetiva, por lo tanto, se exige culpabilidad del cargador, sus agentes o dependientes y como se trata de un contrato que cede en beneficio de cargador y transportista, se responde de culpa leve, agregándose que ella no se presume, sino que debe ser acreditada por quien la alega ${ }^{126}$. Sin perjuicio de ello si la responsabilidad deriva de la infracción de una obligación del cargador, por ejemplo, porque no describió de manera fidedigna la mercadería que embarca o no advirtió su peligrosidad, corresponde al cargador acreditar su debida diligencia, por aplicación de la regla general del art. 1547 inciso $3^{\circ}$ del $C C^{127}$.

Para concluir con este punto, debe agregarse que, de conformidad con lo dispuesto en el art. $1031 \mathrm{del} C$. de $C$., es necesario dar un aviso previo para hacer efectiva esta responsabilidad. A falta de aviso, se genera una presunción simplemente legal de inexistencia de pérdida o daño que, por lo tanto, admite prueba en contrario. La falta de aviso no genera una sanción tan gravosa para el transportista, el cual siempre debe probar la pérdida o daño cuya indemnización demanda ${ }^{128}$.

\section{Remedios frente al incumplimiento del consignatario}

a) Tratándose de la obligación de recibir la mercancía

$\mathrm{El}$ art. 983 letras b) y c) del $C$. $d e C$., contempla dos formas de hacer la entrega en destino en caso que el consignatario no esté dispuesto a recibirlas;

${ }^{125}$ Barroilhet (2014), p. 467.

${ }^{126}$ Es discutible que esta culpa deba ser probada, como explica Claudio Barroilhet, ya que -estando dentro de la responsabilidad contractual- no se advierte ninguna razón para hacer excepción a la regla del art. 1547 inciso $3^{\circ}$ del Código Civil. En todo caso, cabe tener presente que también se puede originar responsabilidad extracontractual, dependiendo de la naturaleza del hecho generador del daño y, en tal caso, sí tendría cabida la prueba de la culpa. Por otro lado, también resulta discutible que se responda de culpa leve, atendido el tenor de la ley al reglamentar la prueba liberatoria.

${ }^{127}$ Barroilhet (2014), pp. 467-468.

${ }^{128}$ Op. cit., p. 468. 
la primera, consiste en poner las mercancías a disposición del consignatario, en conformidad con el contrato, las leyes o los usos del comercio de que se trate, aplicables en el puerto de descarga; la segunda, consiste en ponerlas en poder de una autoridad u otro tercero a quienes, según las leyes o los reglamentos aplicables en el puerto de descarga, hayan de entregarse las mercancías. Sin perjuicio de ello, el transportista también podría hacer uso del pago por consignación contemplado en el art. 1.598 y siguientes del Código Civil ${ }^{29}$.

En este sentido, todo indica que esta "obligación" sería más bien un caso de colaboración del acreedor ${ }^{130}$, como deber secundario, funcional o instrumental en el contrato ${ }^{131}$, ya que se advierte una necesidad efectiva de que el consignatario colabore recibiendo el pago ofrecido por el transportista ${ }^{132,133}$. En consecuencia, si el consignatario no cumple con este deber secundario de recibir las mercancías, se estaría frente a un incumplimiento contractual que da lugar a la correspondiente acción indemnizatoria $^{134}$.

Por otro lado, por razones prácticas, no podrían tener cabida otros remedios contractuales como la rebaja del precio o la sustitución de las mercancías.

64 b) Tratándose de la obligación de pagar el flete

Según el art. 865 del C. de C., en principio, el transportista no podrá retener las mercancías al tiempo de la descarga por el hecho de no habérsele pagado el flete. Sin embargo, de manera excepcional, se le permite pedir la retención judicial de las mismas para asegurar el pago de su acreencia ${ }^{135}$.

Como consecuencia de ello, se entiende que no habría inconvenientes en que el transportista pueda demandar la pretensión de cumplimiento específico o la indemnización de perjuicios. Empero, otros remedios, como la rebaja del precio y la sustitución de las mercancías, no podrían tener cabida por razones prácticas.

${ }^{129}$ Barroilhet (2014), p. 487.

${ }^{130}$ Prado (2015a), p. 101.

${ }^{131}$ Op. cit., p. 112.

132 Op. cit., p. 83.

${ }^{133}$ Conviene advertir que, para que pueda surgir este caso de colaboración del acreedor, es necesario que el consignatario haya aceptado, pues solo en virtud de esa aceptación está en condiciones de reclamar el cumplimiento de lo estipulado y, por lo mismo, se considera acreedor en la obligación de recibir las mercaderías.

${ }^{134}$ Op. cit., p. 160.

${ }^{135}$ Barroilhet (2014), p. 803. 


\section{Conclusiones}

A partir de lo expuesto, ha sido posible demostrar que las disposiciones del Código de Comercio chileno en materia de contrato de transporte marítimo bajo régimen de conocimiento de embarque son compatibles con la concepción de contrato del nuevo derecho de la contratación. De esta manera, es posible observar que la estructura, incumplimiento y remedios contractuales del referido contrato, son susceptibles de ser analizados desde la perspectiva del nuevo derecho de la contratación.

Como consecuencia de lo anterior, puede advertirse, en materia de estructura, que este contrato da origen a un conjunto de relaciones jurídicas, pudiendo distinguirse con claridad entre obligaciones principales o primordiales, que efectivamente permiten la satisfacción de los intereses de las partes (conducir las mercancías y pagar el flete) y obligaciones secundarias o funcionales (como cuidar las mercancías, entregar la documentación necesaria para el transporte, suministrar una determinada temperatura, etc.). De acuerdo con esto, no es posible identificar a unos únicos acreedor y deudor, sino que es preferible hablar de partes o contratantes, pues, dependiendo de la obligación de que se trate, las calidades de acreedor y deudor se van intercambiando. Lo anterior aparece todavía más claro en el contrato de transporte marítimo bajo régimen de conocimiento de embarque, pues, dependiendo de la obligación de que se trate, el acreedor puede ser el cargador, el transportista o el consignatario.

Por otro lado, siempre en el ámbito de la estructura contractual, podemos advertir que algunas obligaciones que de manera tradicional se ha señalado que genera este contrato, en realidad corresponderían a casos de colaboración del acreedor, cuya inejecución puede dar lugar a la correspondiente indemnización de perjuicios; esto es lo que ocurre, por ejemplo, con la obligación del consignatario de recibir las mercancías que le ofrece el transportista.

En materia de incumplimiento, también es posible adoptar la concepción abstracta y objetiva del nuevo derecho de la contratación, entendiendo que lo hay cuando se verifica cualquiera desviación del programa contractual, sin necesidad de entrar a calificar la imputabilidad del mismo. Tal calificación tendrá relevancia a la hora de determinar la procedencia de ciertos remedios contractuales como ocurre, según lo señalado por la doctrina, con la indemización de perjuicios; en cambio, tratándose de otros, como la pretensión de cumplimiento específico o la rebaja del precio, la imputabilidad resulta ser ajena.

De la misma manera, en materia de remedios contractuales, la amplitud de ellos que plantea el nuevo derecho de la contratación en caso de incumplimiento resulta perfectamente compatible con las disposiciones 
del Código de Comercio que regulan el contrato de transporte marítimo bajo régimen de conocimiento de embarque. Si bien, desde un punto de vista práctico, el remedio indemnizatorio es el más utilizado y es el que aparece reglamentado con detalle por el legislador mercantil, nada impide que el acreedor pueda hacer uso de cualquiera de los otros que establece el ordenamiento jurídico, pues se sostiene, por la doctrina contemporánea, que el acreedor tiene libertad para elegir el remedio contractual que mejor satisfaga su interés, cumplidos que sean sus requisitos de procedencia. En este sentido, la rebaja del precio (en este caso, la rebaja del flete) puede ser un remedio idóneo para ser aplicado junto a la indemnización de perjuicios; de la misma manera, otro remedio por el que puede instar el acreedor es la sustitución de las mercancías, tratándose de obligaciones genéricas.

La rebaja del precio cobrará importancia cuando el transportista marítimo no entregue la totalidad de la mercancía recibida de parte del cargador (pérdidas) o, bien, la entregue con desperfectos (mermas). Como ha podido advertirse, el problema deberá resolverse atendiendo a la modalidad en que se ha recibido la mercancía. Si se trata de la modalidad "FCL/FCL", se entiende que el transportista ha recibido un contenedor cerrado y sellado, de manera que si entrega lo mismo en destino, no habrá habido incumplimiento y, por lo mismo, no procedería la rebaja del flete. En cambio, tratándose de la modalidad "LCL/LCL", el transportista recibió mercancía aislada, correspondiéndole a él la carga y estiba al interior del contenedor; por lo que, en caso de pérdida o merma, procedería la rebaja del flete.

De esta manera, como el contrato se concibe como un medio de distribución de riesgos entre las partes (quién asume el riesgo de la inejecución), si el contrato se celebró bajo modalidad "FCL/FCL", es el cargador quien ha cargado y estibado la mercancía en el interior del contenedor, por lo que el riesgo de pérdida o merma es ajeno a la esfera de control del transportista, lo que se traduce en que este no puede hacerse responsable por tales pérdidas o daños, ya que en la distribución del riesgo, el incumplimiento por pérdidas o daños ha sido puesto dentro de la esfera de control del cargador. Por idénticas razones, no procedería la sustitución de las mercancías como remedio contractual.

La situación es distinta cuando se ha contratado bajo la modalidad "LCL/LCL", pues, en este caso, el transportista recibió mercancía aislada y, por lo mismo, la estiba y carga de la misma al interior del contenedor está dentro de su esfera de control, de manera que, en caso de pérdidas o daños, procederían en su contra los remedios de rebaja del flete y de sustitución de las mercancías.

Desde otra perspectiva, y dado que el paradigma establecido por el nuevo derecho de la contratación es el de la obligación de objeto fungible, 
la causa extraña opera más bien como causal de exoneración de responsabilidad y no como modo de extinguir las obligaciones, de lo que se sigue que -si la mercancía está constituida por cosas genéricas- la ocurrencia de un caso fortuito excluye la posibilidad de reclamar la indemnización de perjuicios, pero no obsta a la de exigir la pretensión de cumplimiento específico, la resolución, la rebaja del precio o la sustitución de las mercancías, cumpliéndose los presupuestos propios de cada remedio contractual.

\section{Bibliografía CitADA}

Abeliuk Manasevich, René (2014). Las obligaciones. Santiago: Thomson Reuters. Alessandri Rodríguez, Arturo (1998). Teoría de las obligaciones. Santiago: Editorial Jurídica Ediar Conosur.

Alessandri Rodríguez, Arturo; Manuel Somarriva Undurraga, Antonio VoDANOvic HaKlicka (1942). Curso de derecho civil. Fuentes de las obligaciones. Santiago: Editorial Nascimento.

Alessandri Rodríguez, Arturo; Manuel Somarriva Undurraga, Antonio VoDANOVIC HAKLICKA (2016). Tratado de las obligaciones. Volumen de las obligaciones en general y sus diversas clases. Santiago: Ediciones Jurídicas de Santiago.

Barrientos Camus, Francisca (2014). "La articulación de remedios en el sistema de la responsabilidad civil del consumo". Revista de Derecho de la Pontificia Universidad Católica de Valparaíso. Vol. XuI, Valparaíso, $1^{\mathrm{er}}$ semestre.

Barroilhet Acevedo, Claudio (2014). Derecho marítimo. Santiago: Librotecnia.

Barroilhet Acevedo, Claudio y Alejandro Díaz Díaz (2002). El derecho del transporte. Santiago: Libromar. Tomo I.

Brantt Zumarán, María Graciela (2010). El caso fortuito y su incidencia en el derecho de la responsabilidad civil contractual. Santiago: Abeledo Perrot.

Buffelan-Lanore, Yvaine et Virginie Larribau-Terneyre (2014). Droit Civil. Des Obligations. Mayenne: Sirey.

Carvallo Soto, Jaime (1994). Derecho marítimo chileno. Santiago: Ediciones Jurídicas La Ley.

Contreras Strauch, Osvaldo (2000). Derecho marítimo. Santiago: Editorial Jurídica Conosur Ltda.

Cornejo Fuller, Eugenio (2003). Derecho marítimo chileno. Explicaciones sobre el libro III del Código de Comercio: De la navegación y el comercio marítimos. Valparaíso: Ediciones Universitarias de Valparaíso.

Corral Talciani, Hernán (2010). Contratos y daños por incumplimiento. Santiago: Abeledo Perrot.

Corral TAlCiani, Hernán (2013). Lecciones de responsabilidad extracontractual. Santiago: Thomson Reuters. 
Court Murasso, Eduardo y Veronika Wegner Astudillo (2013). Derecho de las obligaciones. Santiago: Thomson Reuters.

De Pablo Contreras, Pedro, Miguel Ángel Pérez Álvares, María Ángeles Parra LuCÁn (2014). Derecho Civil (II). Derecho de Obligaciones. Madrid: Colex.

García Infante, Félix (1993). Derecho del transporte marítimo. Comentarios, legislación comercial y administrativa. Valparaíso: Ediciones Universitarias de Valparaíso.

Josserand. Louis (2008). Teoría general de las obligaciones. Santiago: Editorial Parlamento Ltda.

Lobato Gómez, J. Miguel (1992). "Contribución al Estudio de la Distinción entre las obligaciones de medios y las obligaciones de resultado". Anuario de Derecho Civil. Tomo. 45, Fascículo n. ${ }^{\circ}$ 2, Madrid, disponible en www.boe.es/publicaciones/anuarios_derecho/abrir_pdf.php?id=ANU-C-1992-20065100734_ ANUARIO_DE_DERECHO_CIVIL_Contribuci\%F3n_al_estudio_de_la_ distinci\%F3n_entre_las_obligaciones_de_medios_y_las_obligaciones_de_resultado [Fecha de consulta: 4 de julio de 2017].

Llambías, Jorge Joaquín, Patricio Riffo Benegas, Rafael Sassot, (2005). Manual de derecho civil. Obligaciones. Buenos Aires: LexisNexis.

López DíAz, Patricia (2010) "La indemnización compensatoria por incumplimiento de los contratos bilaterales como remedio autónomo en el derecho civil chileno". Revista Chilena de Derecho Privado. N. ${ }^{\circ}$ 15. Santiago. Diciembre.

López DíAz, Patricia (2015) La autonomía de la indemnización de daños por incumplimiento de un contrato bilateral en el Código Civil chileno. Santiago: Thomson Reuters.

López Santa María, Jorge y Fabián Elorriaga De Bonis (2017). Los contratos. Parte general. Santiago: Abeledo Perrot.

Mejías Alonzo, Claudia (2011). El incumplimiento resolutorio en el Código Civil. Santiago: Abeledo Perrot.

Meza Barros, Ramón (2007). Manual de Derecho Civil. De las obligaciones. Santiago: Editorial Jurídica de Chile.

Monterroso Casado, Esther (2014). Derecho Civil. Derecho de obligaciones. Madrid: Ediciones CEF.

Morales Moreno, Antonio (2006). La modernización del derecho de las obligaciones. Madrid: Thomson Civitas.

Peñallillo Arévalo, Daniel (2003). Obligaciones. Teoría general y clasificaciones. La resolución por incumplimiento. Santiago: Editorial Jurídica de Chile.

Peñailillo Arévalo, Daniel (2009). "Responsabilidad contractual objetiva", en Estudios de Derecho Civil IV. Jornadas Nacionales de Derecho Civil. Olmué, 2008. Santiago, Editorial Legal Publishing.

Pizarro Wilson, Carlos (2008a). "Hacia un sistema de remedios al incumplimiento contractual", en Estudios de Derecho Civil III. Jornadas Nacionales de Derecho Civil. Valparaíso, 2007. Santiago: Legal Publishing. 
Pizarro Wilson, Carlos (2008b). "La culpa como el elemento constitutivo del incumplimiento en las obligaciones de medio o de diligencia". Revista de Derecho de la Pontificia Universidad Católica de Valparaíso. Vol. Xxxi. Valparaíso. $2^{\circ}$ semestre.

Pothier, Joseph (1993). Tratado de las obligaciones. Buenos Aires: Editorial Heliasta S.R.L.

Prado López, Pamela (2012). “¿Es aplicable en Chile la concepción de contrato adoptada por el nuevo derecho de la contratación?”, en Fabián ElorriagA (coord.). Estudios de Derecho Civil VII.Jornadas Nacionales de Derecho Civil. Viña del Mar. 2011. Santiago: Thomson Reuters.

Prado LóPez, Pamela (2013). "La rebaja del precio como remedio contractual en el derecho civil chileno: una aproximación”, en Carmen Domínguez, Joel González, Marcelo Barrientos, Juan Luis Goldenberg (coords.), Estudios de Derecho Civil VIII. Jornadas Nacionales de Derecho Civil. Santa Cruz, 2012. Santiago: Thomson Reuters.

Prado López, Pamela (2015a). La colaboración del acreedor en los contratos civiles. Santiago: Thomson Reuters.

Prado López, Pamela (2015b). "La cuantificación de la rebaja del precio en la acción Quanti Minoris”. Ius et Praxis. Año 21. n. ${ }^{\circ}$ 1. Talca.

Ramos Pazos, René (2008). De las obligaciones. Santiago: Legal Publishing.

Ruz LÁrtiga, Gonzalo (2011). Explicaciones de derecho civil. Obligaciones. Santiago: Abeledo Perrot. Tomo II.

Salinas UGarte, Gastón (2011). Responsabilidad civil contractual. Santiago: Abeledo Perrot.

TAmayo Jaramillo, Javier (2007). Tratado de responsabilidad civil. Bogotá: Editorial Legis.

Tomasello Hart, Leslie (2014). Curso de derecho marítimo chileno. Santiago: Libromar.

Troncoso Larronde, Hernán (2011). De las obligaciones. Santiago: Thomson Reuters.

Vidal Olivares, Álvaro (2007a). "La pretensión de cumplimiento específico y su inserción en el sistema de remedios por incumplimiento en el Código Civil", en Hernán Corral, Ma Sara Rodríguez (coords.). Estudios de Derecho Civil II. Santiago: Lexis Nexis.

Vidal Olivares, Álvaro (2007b). "Cumplimiento e incumplimiento contractual en el Código Civil. Una perspectiva más realista”. Revista Chilena de Derecho. Vol. 34, n. ${ }^{\circ}$ 1. Santiago.

Vidal Olivares, Álvaro (2009a). "El incumplimiento de obligaciones con objeto fungible y los remedios del acreedor afectado. Una relectura de las disposiciones del 'Código Civil' sobre incumplimiento", en Alejandro GuZMÁN (editor científico). El Código Civil de Chile (1855-2005). Trabajos expuestos en el Congreso Internacional Celebrado para conmemorar su promulgación (Santiago, 3-6 de octubre de 2005). Santiago: Legal Publishing. 
Vidal Olivares, Álvaro (2009b). "La noción de incumplimiento esencial en el Código Civil”, en Revista de Derecho de la Pontificia Universidad Católica de Valparaíso. Vol xxxII, Valparaíso Primer semestre.

Vidal Olivares, Álvaro (2011). "El incumplimiento y los remedios del acreedor en la propuesta de modernización del derecho de las obligaciones y contratos español", en Revista Chilena de Derecho Privado, $\mathrm{N}^{\circ} 16$. Santiago.

VidAl Olivares, Álvaro (2014). "Responsabilidad civil por incumplimiento de obligaciones con objeto fungible”, en Í̃nigo De LA MAZA - Antonio Morales, Álvaro VIDAL. Estudios de derecho de los contratos. Santiago: Thomson Reuters.

Vidal Olivares, Álvaro (2017). "La protección del comprador en el Código Civil: Desde la fragmentación a un modelo unitario como instrumento eficaz para la resolución de conflictos en torno al incumplimiento del vendedor", en Juan Ignacio Contardo, Íñigo De la Maza (dirs.), La compraventa. Estudios. Santiago: Thomson Reuters. 